\title{
Non-sustained ventricular tachycardias, conduction disorders and an impaired left ventricular ejection fraction in a 32-year-old woman
}

\section{S. Alsters · Y. Polyukhovych · H. Bikker · L. Wong · A. C. Houweling}

Published online: 28 August 2019

(C) The Author(s) 2019

A 32-year-old woman was referred for cardiological evaluation due to palpitations. She did not have a history of syncope. Her family history was negative for sudden death. Electrocardiography showed a sinus rhythm with a first-degree atrioventricular (AV) block (PR interval $310 \mathrm{~ms}$ ) and premature ventricular contractions (Fig. 1a). A monomorphic non-sustained ventricular tachycardia was seen on Holter recording. Cardiac MRI showed an impaired left ventricular ejection fraction (LVEF) of $41 \%$ with mid-myocardial late enhancement consistent with cardiomyopathy (Fig. 1b). DNA analysis revealed a previously reported pathogenic mutation, c.1130G $>$ A p.(Arg377His) in the LMNA gene. The cardiac phenotype associated with mutations in the $L M N A$ gene typically includes earlyonset AV conduction disorders, tachyarrhythmias, dilated cardiomyopathy, in some cases associated with skeletal myopathy $[1,2]$. The presence of non-sustained ventricular tachycardias, LVEF $<45 \%$ at first evaluation, male sex and non-missense mutations (e.g. ins-del/truncating or mutations affecting splicing) are associated with an increased risk of malignant ventricular arrhythmias in LMNA mutation carriers [3].
Conflict of interest S. Alsters, Y. Polyukhovych, H. Bikker, L. Wong and A.C. Houweling declare that they have no competing interests.

Open Access This article is distributed under the terms of the Creative Commons Attribution 4.0 International License (http://creativecommons.org/licenses/by/4.0/), which permits unrestricted use, distribution, and reproduction in any medium, provided you give appropriate credit to the original author(s) and the source, provide a link to the Creative Commons license, and indicate if changes were made.

\section{References}

1. van Rijsingen IA, Nannenberg EA, Arbustini E, etal. Genderspecific differences in major cardiac events and mortality in lamin A/C mutation carriers. Eur J Heart Fail. 2013;15:376-84.

2. Peretto G, Sala S, Benedetti S, et al. Updated clinical overview on cardiac laminopathies: an electrical and mechanical disease. Nucleus. 2018;9:380-91.

3. van Rijsingen IA, Arbustini E, ElliottPM, etal. Riskfactors for malignant ventricular arrhythmias in lamin a/c mutation carriers a European cohort study. J Am Coll Cardiol. 2012;59:493-500.

\footnotetext{
S. Alsters · A. C. Houweling $(\bowtie)$

Department of Clinical Genetics, Amsterdam UMC, Vrije

Universiteit Amsterdam, Amsterdam, The Netherlands

a.houweling@vumc.nl

Y. Polyukhovych $\cdot$ L. Wong

Department of Cardiology, Amsterdam UMC, Vrije

Universiteit Amsterdam, Amsterdam, The Netherlands

H. Bikker

Department of Clinical Genetics, Amsterdam UMC,

University of Amsterdam, Amsterdam, The Netherlands
} 


\section{Heart Beat}
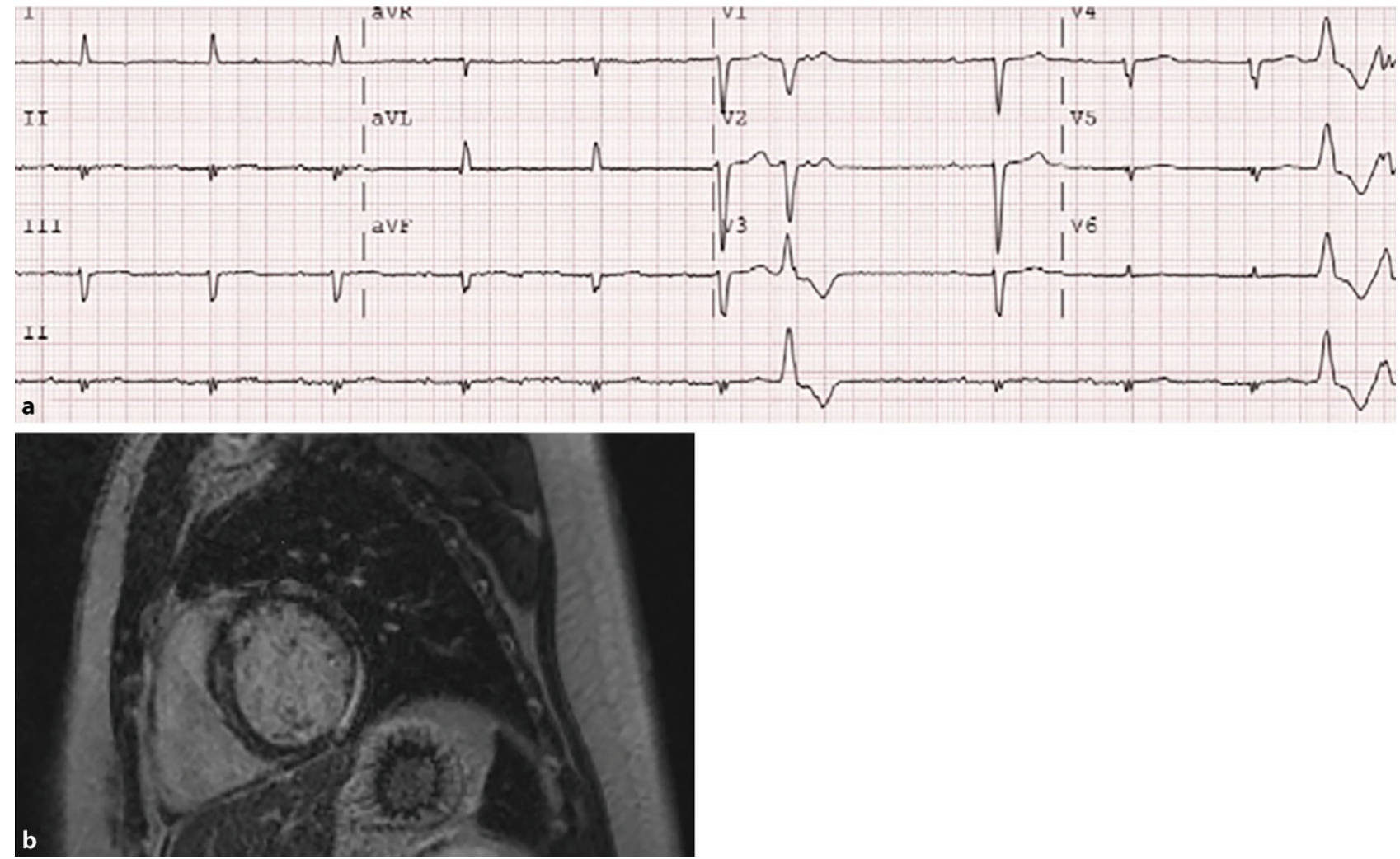

Fig. 1 a Electrocardiogram. b Cardiac MRI 